\title{
Development and metabolism of the city of Khartoum (Republic of Sudan): spatial designing of the coastal territory of the Blue and White Nile
}

\author{
Ilhomjeon Shakurov ${ }^{1 \mathrm{a}}$, Ahmed Elamin ${ }^{1}$, and Mohammed Zebilila ${ }^{1}$ \\ ${ }^{1}$ Moscow State University of Civil Engineering, 129337, Moscow, Russia
}

\begin{abstract}
The given article reveals the development of the metabolism of the city of Khartoum, the problems of influence on the microclimate improvement elements built up coastal territory of the Blue and White Nile in Khartoum. The study shows the microclimate formation factors of Khartoum, gives an assessment of the modern state of the microclimate of the coastal zone and its changes. The article indicates that, depending on the nature of use and planning organization of coastal territories microclimatic influence of water areas can propagate over appreciable distances to the city or limitation depth in a narrow strip along the coast. In urban areas the air temperature is considerably higher and the humidity is lower than in the coastal area especially in summer, this is due to differences in physical properties of water and land. Water has a higher heat capacity, high reflectivity, the wind speed increases and increasing the humidity of air masses passing over it. Thus, in order to improve microclimatic and hygienic conditions of coastal territories in Khartoum there is the need to use the favorable impact of the Blue and White Nile.
\end{abstract}

Sudan, a country of deserts and savannah, but this general definition hides a wide variety of environmental conditions. It is not due to the so much differences in topography (as most of the country is slightly dissected plateau), but the difference in the latitudinal position, which determines the climatic conditions. The territory of the country is located within an ancient African platform. Change of the width zones - from the "classical" desert in the north to rainforests in the south is well expressed. The surface of Sudan - almost a plain raised on height of 500-1000 $\mathrm{m}$ above sea level. Its heights increase to the West, the East and the South.

The largest city of Khartoum - the capital of the Republic of Sudan, the state in the northeast of Africa. Khartoum is located in the central part of Sudan, located in a place where the White and Blue Nile are merged, and is flowing as the Nile River, which is flowing through Egypt and flows into the Mediterranean Sea. The city is located on the elongated promontory on the left bank of the Blue Nile at an altitude of $400 \mathrm{~m}$ above sea level. The confluence is of the form of an elephant's trunk, (al-Khartûm - an elephant's trunk in Arabic). Hence the name of the city [1].

${ }^{a}$ Corresponding author: shukurov2007@yandex.ru 
The climate of Khartoum is characterized by:

- Exhausting warm summer climate;

- Large volatility and low relative humidity during the hot period;

- A small annual sum of precipitation;

- Slight wind speed;

- Availability of breeze phenomena with a daily change in direction of coastal areas of the Blue and White Nile.

With a research objective of finding the influence of the Blue and White Nile on coastal strips we carried out the analysis of the design and experience of construction of coastal settlement, and field observation in this territory [2].

An analysis of existing work and experience in the design of the coastal strip in Khartoum allows us to conclude that at present there is no generally agreed evidence-based approach for accounting the impact of the Blue and White Nile in the urban metabolism and microclimate of the city of Khartoum.

In several cases, a differentiated approach is not practiced to the planning and settlement of separate urban areas, which are located in complicated geographical conditions and are characterized by various levels of beautification.

In carrying out field observations for the changes in temperature and humidity Assman's psychrometer and M-22 s and M-16s recorders were used. Speed and the direction of the wind were measured by M.s-13 cup anemometer and a directional sign. Before measurement, calibration of devices was carried out. The general weather conditions near Khartoum were taken from the meteorological station "Airport".

In observing the temperature, humidity and wind mode there was a simultaneous revelation of the influence of green plantings and types, underlying surfaces with different radiation characteristics in coastal and remote areas, located in the settlement, as well as out of it [3].

Observations have shown that during the day the temperature of sun-lit area of the surface of the sandy soil, lawn is on the average lower by $15-20^{\circ} \mathrm{C}$, than the temperature of the surface of loamy soil and asphalt, and the maximum difference is $45^{\circ} \mathrm{C}$. The maximum surface temperature observed was from the period from 8 hours to 19 hours.

It is known that the underlying surface heats adjacent layers of air. It is therefore expected that air temperature in all cases has to be lower than temperature of the underlying surface. However, it was only appropriate for the lit surfaces. Air temperature over sand was $4-6^{\circ} \mathrm{C}$ lower in the morning and in the evening, and the maximum difference of $42.4{ }^{\circ} \mathrm{C}$ was observed at 17 hours. Over the lawn, this difference of $4{ }^{\circ} \mathrm{C}$ was constant until 16 o'clock, and subsequent air temperature exceeded lawn surface temperature by $3-$ $5{ }^{\circ} \mathrm{C}$. The air temperature over the lawn and sand is below that over asphalt, on average by $4.8^{\circ} \mathrm{C}$. Sometimes this difference reached $5{ }^{\circ} \mathrm{C}$. The air temperature over the sand and lawn were characterized by small amplitudes of fluctuations during the period of observation as seen in similar data over asphalt pavements [4].

Air temperature over a lawn and the soil under tree crowns (in shade) is always below, that over asphalt pavements, and the difference in temperature reaches $48^{\circ} \mathrm{C}$. Distinction of air temperatures over the lit and shaded surfaces of the lawn and sand was about 8.5$11.5^{\circ} \mathrm{C}$. Under crowns, relative humidity of air is by $15-20 \%$ more than similar lit underlying surfaces.

Process of change of air temperature by green plantings was seen to be the opposite process of the change of air temperature of the underlying surfaces. Under tree crowns, air temperature was higher than soil surface temperature, and the difference reached $11-14{ }^{\circ} \mathrm{C}$. This phenomenon is explained by advection of air masses from more heated adjacent surfaces. 
In the zone of influence of the Blue and White Nile green plantings are capable of preserving such influence on a microclimate settlement. So, with a distance from the rivers, in a zone of green plantings $250 \mathrm{~m}$ wide the change of air temperature was 2$2.8{ }^{\circ} \mathrm{C}$, and humidity of air was only $12-14 \%$. Whereas in territories that were not planted with trees and shrubs the corresponding differences reached $1-3.5^{\circ} \mathrm{C}$, and humidity of 4 $10 \%$. Wind speed in a green zone far from the rivers decreased by two and a half times, than in the coastal territory which was not planted with trees and shrubs in similar conditions. Paths between green plantings promote the direct flow of air from Blue and White Nile to the settlement [5].

In studying the influence of the Blue and White Nile on the urban metabolism and microclimate mode of the city of Khartoum, we conducted field observations. The field observations carried out determined that the change of the microclimate parameters of the settlement was due to the influence of the Blue and White Nile, which is noticed in areas of $2200 \mathrm{~m}$ wide. With increasing distance from the river predominant impact on microclimate areas are on buildings, artificial pavement, beautification and the like elements. The degree of influence of the river changes throughout the day. Thus during morning hours air temperature difference between the water and land surface layers is $3-7^{\circ}$ $\mathrm{C}$, and $6-9{ }^{\circ} \mathrm{C}$ in the daytime. Air humidity changes between $20-24 \%$, wind speed from 0 to $2.5 \mathrm{~m} / \mathrm{s}$. Changes in temperature and humidity and wind regime in the development, which is formed under the influence of the river is shown in Figure 1.

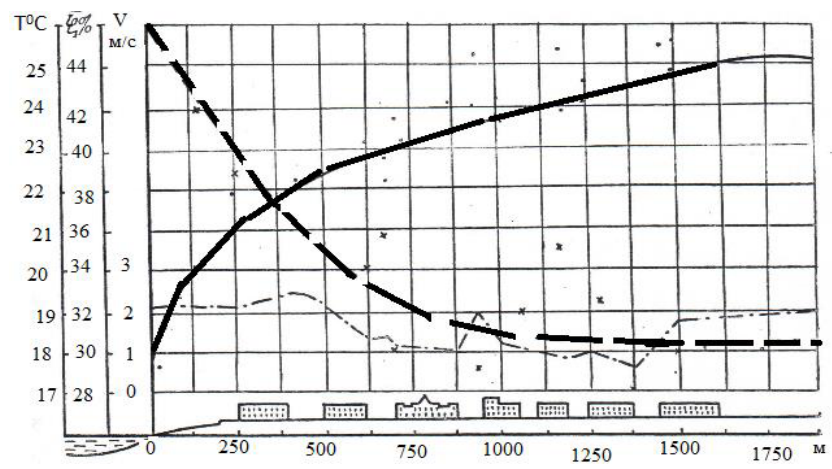

air temperature

- - humidity

- - w wind speed

Fig.1. Change of microclimatic parameters of a microclimate in building settlement of a coastal zone.

Irregularity and different nature of microclimatic characteristic plots of urban environment also determines the various planning decisions of housing areas, especially in the Blue and White Nile.

Based on the results of the field observations changing in air humidity in the settlement $\Delta \bar{\varphi}$ is determined by the formula:

$$
\Delta \bar{\varphi}=\left(\bar{\varphi}_{B}-\bar{\varphi}_{c}\right) \times\left(1-m_{B} \ln ^{2} L_{B}\right) \cdot n \cdot d,
$$

where $\bar{\varphi}_{B}$ - Air humidity from the water's edge at a height $1.5 \mathrm{~m}$ from the ground level, \%; $\bar{\varphi}_{c}-$ Air humidity outside the zone of influence of the river to the settlement at a height of $1.5 \mathrm{~m}$ from the ground, $\%$;

$m_{B}$ - Coefficient depending on the size of the river in the direction of the wind, the ratio of the turbulence coefficient to the wind speed equal to 0.02 ;

$L_{B}$ - Width of the zone of the river's influence to air humidity, m;

$n$ - The coefficient considering the change in speed of wind depending on the height of buildings and the locality (territory roughness); 
$d$ - The aerodynamic coefficient for vertical surfaces, taken as 1.1 for windward side and 0.85 for leeward side.

Air streams generally come from Blue and White Nile. The wind pattern of building settlement depends on the direction of the dominating wind and the planning scheme of streets. Thus, despite variety in the directions of a wind, there exists a well-defined flow path of wind. So, for example, for winds coming from the river, the main air streams are directed along streets, perpendicular to the riverbed of Blue and White Nile [6].

On the entrance to building settlement under the influence of compressed wind stream the relative speed of the wind is $0.2-0.4$ higher than speed in undeveloped territories. In building settlement wind streams are sent along streets and through spaces between buildings.

The disorderly movement of wind streams is noted at intersections, on streets, on undeveloped sites, between buildings and trees. Between buildings of width $0.6-0.8 \mathrm{H}$ wide ( $\mathrm{H}$ - the accepted building height) the speed of the wind increases in gaps by $0.2-0.4$ of the speed in undeveloped territory. The air stream is divided into separate streams, part of which comes to quarters of the cross street.

At a deviation from the main direction of a wind at an angle less than $45^{\circ}$ the direction of the movement of streams on streets remains the same, as well as the direction of the main wind taking the direction of the longitudinal streets.

At a wind direction of an angle closer to $45^{\circ}$ to the front of the building settlement the main air streams go in the directions seeking to meet with the main wind direction, i.e. as if in steps formed by sites of mixed and crossed streets [7].

Thus, the wind directed from the river is capable of increasing the extent of influence of Blue and White Nile on the temperature, humidity and wind pattern of the building settlement of coastal zone. For wind streams of opposite direction, the impact of the rivers on the microclimate of the building settlement is less significant.

Based on the conducted field research, a microclimatic zoning for the territories of the city was carried out. The following are characteristic zones developed for the city:

The first area, which is directly adjoining Blue, White Nile and beginning from the water edge where, parameters of a microclimate have values close to values of surface layer of air. So, changes of temperature, humidity and wind pattern is: $\Delta \mathrm{T}=4-9{ }^{\circ} \mathrm{C}$, $\Delta \bar{\varphi}=12-24 \%$, To $=1.2-2.5$.

The second area - a buffer zone along building settlement of the coastal territory, which the settlement has an impact on. The width of this zone is about $160-250 \mathrm{~m}$ and where changes of parameters of a microclimate respectively is $\Delta \mathrm{T}=2-7{ }^{\circ} \mathrm{C}, \Delta \bar{\varphi}=6-18 \%$, To $=0.8-1.8$.

The third area - under direct influence of the river on the formation and change of a microclimate of building settlement $800 \mathrm{~m}$ wide. In this zone change of parameters of the microclimate respectively is: $\Delta \mathrm{T}=0.8-4.5^{\circ} \mathrm{C}, \Delta \bar{\varphi}=8-13 \%$, To $=0.7-1.5$.

The fourth area - periodic influence of the river depending on the direction of the wind and the breeze phenomena in the coastal zone. In this zone the influence of the "city" on formation of the temperature, humidity and wind pattern is more noted: $\Delta \mathrm{T}=0.4-1.5^{\circ} \mathrm{C}$, $\Delta \bar{\varphi}=4-8 \%$, To $=0.3-0.9$.

The fifth area - with a small density of buildings with considerable open spaces and the areas of artificial coverings, where influence of the river affects to a lesser extent.

The sixth area with building blocks, creating closed limited spaces with the microclimate, which is formed under the influence of beautification elements. Changes of the temperature, humidity and wind conditions have small values and influences $\left(\Delta \mathrm{T}=0.5-1{ }^{\circ} \mathrm{C}\right.$ are explained by a conservative nature and resilience to external influence; $\Delta \bar{\varphi}=6-12 \%$; To $=0.2-0.6)$.

According to the degree of influence on the microclimate of the building settlement by the river four zones of the territory of Khartoum are identified: 
a) Lower terrace of a coastal slope;

b) Zone between a brow of a coastal slope and the front of building settlement;

c) The built-up territories experiencing continuous microclimatic influence of the river;

d) The built-up territories coming under the incidental (unstable) influence of water bodies.

Thus, the analysis of results of the observation allows to draw similar conclusion, that the underlying surfaces possessing property to reduce amplitudes of fluctuation of temperature and humidity of air (lawns, bushes, green plantings) promote improvement of the microclimate of the territory and increase in the zone of influence of Blue and White Nile.

A small area of trees and plants contribute to the overall reduction of air temperature and reduction in humidity, comparable to filters, allowing in air of the surrounding areas and cooling it. Thus, by appropriate landscaping it is possible to regulate micro-climatic conditions of the building settlement.

Planting of trees and plants in the zone of influence of Blue and White Nile promotes the positive impact on the temperature, humidity and wind condition of coastal territories of Blue and White Nile.

\section{References}

1. H. Adam, Features planning regular reconstruction of residential one-storey and elemental chaotic building: E.g. Khartoum, Sudan (2002)

2. A. Giyasov, O. Sokolskaya, O. Al Fakri, UP, 6, 58-62 (2012)

3. Guidelines for an assessment and regulation of the wind regime of residential development (1986)

4. S. Chistjakova, C.P. house, 3, 20-28 (1965)

5. I. Shukurov, Problems of the warm and wind mode of the dwelling of Iraq (2008)

6. I. Shukurov, L.I.\&M, 3, 43-46 (2013)

7. I. Shukurov, H.C, 2, 20-21 (2005). 